\title{
Limited value of serum holo-transcobalamin II measurements in the differential diagnosis of macrocytosis
}

\author{
S N Wickramasinghe, I D Ratnayaka
}

\begin{abstract}
Aim-To study the value of serum holotranscobalamin II (holo-TCII) measurements in the differential diagnosis of macrocytosis.

Methods-Holo-TCII concentrations were measured in serum samples from 50 healthy non-vegetarian subjects and $\mathbf{3 0}$ patients with macrocytosis, using a technique based on the adsorption of holoTCII with amorphous, precipitated silica. Deoxyuridine (dU) suppression tests were performed on the bone marrow cells of all the patients. Haematological diagnoses were made using standard criteria.

Results-The causes of macrocytosis were cobalamin (Cbl) deficiency due to pernicious anaemia or following partial gastrectomy (10 patients), dietary folate deficiency with/without $\mathrm{Cbl}$ deficiency (four patients), chronic alcoholism (four patients), myelodysplastic syndrome (five patients), treatment with methotrexate or azathioprine (three patients), and congenital dyserythropoietic anaemia (CDA) (four patients). Undetectable or low holoTCII concentrations were found in all patients with $\mathrm{Cbl}$ deficiency and in some or all patients from each of the other diagnostic categories. There was also no correlation between the dU suppressed value and the holo-TCII concentration: all 15 patients with high dU suppressed values and nine of 15 with normal dU suppressed values, including four patients with CDA, had low holo-TCII concentrations.
\end{abstract}

Conclusions-Measurements of serum holo-TCII concentrations by the silica adsorption method are not of value in the differential diagnosis of macrocytosis. The finding of low serum holo-TCII concentrations in patients with macrocytosis due to causes other than Cbl deficiency may result not only from a state of negative Cbl balance but also from other factors, such as increased utilisation of holo-TCII as a consequence of erythroid hyperplasia.

(F Clin Pathol 1996;49:755-758)

Keywords: holo-transcobalamin II, macrocytosis, deoxyuridine suppressed value.

About $6-20 \%$ of the cobalamin (Cbl, vitamin $\mathrm{B}_{12}$ ) in serum is bound to transcobalamin II, the $\mathrm{Cbl}$ binding serum protein involved in delivering $\mathrm{Cbl}$ to cells. ${ }^{1-3}$ Normally, only some of the TCII molecules contain bound $\mathrm{Cbl}$ and such molecules are termed holo-TCII. It has been proposed that a reduction in the serum holo-TCII concentration may occur as an early sign of negative $\mathrm{Cbl}$ balance in the absence of other biochemical, haematological or neurological manifestations of $\mathrm{Cbl}$ deficiency. ${ }^{4}$ In a recent study none of 13 patients with normal total serum $\mathrm{Cbl}$ and low holo-TCII concentrations and only nine of 30 patients with a low total serum $\mathrm{Cbl}$ and a low holo-TCII concentration were considered to show the effects of tissue $\mathrm{Cbl}$ deficiency. ${ }^{6}$ The present study was undertaken to determine the value of holoTCII measurements in the differential diagnosis of macrocytosis.

\section{Methods}

Thirty patients with macrocytosis who underwent bone marrow aspiration during the course of their investigation were studied. Macrocytosis was diagnosed on the basis of mean corpuscular volume values determined using a Technicon $\mathrm{H} 2$ analyser (Bayer Diagnostics, Basingstoke, UK). Red cell folate concentrations were determined using the Becton Dickinson folate $\left({ }^{125} \mathrm{I}\right)$ radioassay kit. In addition to other standard laboratory investigations the following special investigations were carried out.

DEOXYURIDINE SUPPRESSION TEST

An aliquot of freshly aspirated bone marrow was mixed with heparinised Hanks' solution and used to determine the deoxyuridine suppressed value using the method described by Matthews and Wickramasinghe.

HOLO-TCII MEASUREMENTS

Serum holo-TCII concentrations were measured in 50 healthy, non-vegetarian adults and in the 30 patients. A modification of the method of Das et al based on the adsorption of holo-TCII by silica was used, except that total and holo-TCII depleted serum $\mathrm{Cbl}$ concentrations were determined by the $\mathrm{IM}_{\mathrm{X}} \mathrm{Cbl}$ assay using the $\mathrm{IM}_{\mathrm{X}}$ system (Abbot Diagnostics Division, Maidenhead, Berks, UK). The $\mathrm{IM}_{\mathrm{X}}$ $\mathrm{Cbl}$ assay is a microparticle enzyme immunoassay (MEIA) incorporating microparticles coated with porcine intrinsic factor to bind the Cbl.

Preliminary studies were carried out to determine the extent of removal of holo-TCI and holo-TCII from serum by synthetic amor-
Accepted for publication 4 June 1996 
phous precipitated silica (Sipernat 283 LS) (PQ Corporation, Valley Forge, Philadelphia, USA). Normal serum was incubated with 2.5 ng ${ }^{57} \mathrm{Co}$-cyanocobalamin per $\mathrm{ml}\left({ }^{57} \mathrm{Co}-\mathrm{CNCbl}\right.$; specific activity $10 \mu \mathrm{Ci} / 0.05 \mu \mathrm{g}$; Amersham International) at $37^{\circ} \mathrm{C}$ for one hour and dialysed for 24 hours against phosphate buffered saline $\left({ }^{57} \mathrm{Co}-\mathrm{CNCbl}\right.$ treated serum). Either $30 \mathrm{mg}$ silica powder or $300 \mu \mathrm{l}$ of an aqueous slurry containing $30 \mathrm{mg}$ silica was added to $1 \mathrm{ml}$ of ${ }^{57} \mathrm{Co}-\mathrm{CNCbl}$ treated serum. The mixtures were vortexed, left at room temperature for 10 minutes, centrifuged at $5000 \times$ $g$ for 10 minutes and the supernatants removed. Either $800 \mu$ lof these supernatants or of silica unadsorbed ${ }^{57} \mathrm{Co}-\mathrm{CNCbl}$ treated serum was run on a Sephadex G-200 column as described by Bloomfield and Scott, ${ }^{9}$ collecting $4 \mathrm{ml}$ fractions at a flow rate of $12 \mathrm{ml} /$ hour, and the radioactivity in $1 \mathrm{ml}$ of each fraction determined using a Wallac 80000 gamma counter.

To determine holo-TCII concentrations in serum samples, holo-TCII was removed from serum using a slurry containing $6 \mathrm{~g}$ silica (Sipernat $283 \mathrm{LS}$ ) in $100 \mathrm{ml}$ distilled water; $250 \mu \mathrm{l}$ of the slurry containing $15 \mathrm{mg}$ silica was mixed with $500 \mu \mathrm{l}$ serum, vortexed and left at room temperature for 10 minutes. The mixture was then centrifuged at $5000 \times g$ for 10 minutes. The supernatant fluid was assayed for $\mathrm{Cbl}$ (that is, for holo-TCI and holo-TCIII concentrations) using the $\mathrm{IM}_{\mathrm{X}}$ method, allowing for the dilution caused by mixing with the silica slurry (multiplication factor for dilution, $\times 1.49$ ). Total serum $\mathrm{Cbl}$ concentrations were also measured simultaneously using the $\mathrm{IM}_{\mathrm{X}}$ method and the holo-TCII concentration calculated by subtracting the holo-TCI plus holo-TCIII concentration from the total serum Cbl concentration.

\section{Results}

Figure 1 shows the distribution of radioactivity in the fractions collected by Sephadex G-200 chromatography; the data for the serum treated with silica slurry were corrected for dilution. It is evident that silica did not remove significant amounts of holo-TCI and holo-TCIII (that is, holo-haptocorrin) and removed most of the holo-TCII. In two experiments with silica powder, the percentage removal of holo-TCI was 0.9 and 0.5 and the percentage removal of holo-TCII was 89 and 88 , respectively. In one experiment with silica slurry, the removal of holo-TCI and holo-TCII was $0 \%$ and $87.5 \%$, respectively.

The precision of total serum Cbl measured by the $\mathrm{IM}_{\mathrm{X}}$ method was good, both when assayed in a single run and in different runs, with a coefficient of variation of $3.8 \%$ (serum $\mathrm{Cbl}$ 355-670 ng/l) and 3.4\% (serum Cbl 195$785 \mathrm{ng} / \mathrm{l}$ ), respectively. The coefficient of variation of $\mathrm{Cbl}$ concentrations in aliquots of a single serum sample that were treated separately with silica and assayed in a single run was $4.3 \%$. However, when aliquots of the same serum sample were treated separately with silica and both the untreated and silica treated serum samples were assayed in different runs, the precision for holo-TCII measurements was less satisfactory, with a coefficient of variation of $17.7 \%$; the total $\mathrm{Cbl}$ concentration in the serum sample studied in this way was $289 \mathrm{ng} / 1$ and its holo-TCII concentration was $43.9 \mathrm{ng} / \mathrm{l}$.

The serum holo-TCII concentrations in the 50 healthy adults were log normally distributed, with a median value of $87 \mathrm{ng} / 1$ and $95 \%$ reference limits of 12.9-544.7 ng/l. The serum holohaptocorrin concentrations were also log normally distributed, with a median value of $381 \mathrm{ng} / 1$ and $95 \%$ reference limits of 188 $771 \mathrm{ng} / 1$.

The eventual diagnoses in the 30 patients studied were: pernicious anaemia (nine patients); post-gastrectomy $\mathrm{Cbl}$ deficiency (one patient); dietary deficiency of folate or folate and $\mathrm{Cbl}$ (four patients); chronic alcoholism (four patients); myelodysplastic syndrome (MDS) (five patients); macrocytosis secondary to treatment with methotrexate for rheumatoid arthritis (two patients) or to treatment with azathioprine (one patient); and congenital dyserythropoietic anaemia (CDA) (four patients). In three of the patients with CDA, Cbl and folate independent megaloblastic erythropoiesis was the major abnormality present; the fourth patient had CDA type I.

Fifteen patients had low total serum $\mathrm{Cbl}$ concentrations (that is, $<211 \mathrm{ng} / \mathrm{l}$ by the $\mathrm{IM}_{\mathrm{X}}$ method) and a combination of a low total serum $\mathrm{Cbl}$ and a low holo-TCII concentration was found in all patients with pernicious anaemia, all but one of the patients with nutritional deficiency, one patient each with chronic alcoholism or MDS, and one patient with CDA. The combination of a normal total serum $\mathrm{Cbl}$ and a low holo TCII concentration was found in three patients with CDA, two patients with chronic alcoholism, one patient each with dietary folate deficiency or MDS, and one of the patients on methotrexate. The combination of a normal total serum $\mathrm{Cbl}$ and a normal holo

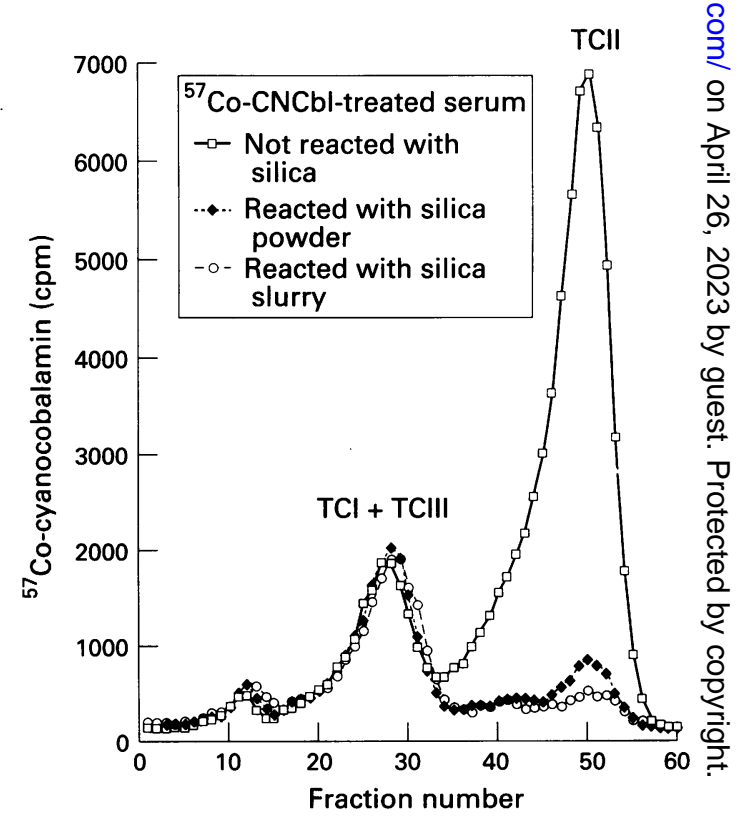

Figure 1 Radioactivity per ml of fractions obtained by Sephadex G-200 chromatography of ${ }^{57} \mathrm{Co}-\mathrm{CNCbl}$ treated serum before and after reaction with silica powder or silica slurry. 
Table 1 Distribution of normal and high deoxyuridine suppressed values (dU-sv) and normal and low holo-TCII concentrations in the various categories of patients studied

\begin{tabular}{|c|c|c|c|c|}
\hline \multirow[t]{3}{*}{ Cause of macrocytosis } & \multicolumn{4}{|c|}{ Number of cases } \\
\hline & \multicolumn{2}{|l|}{$d U-s v$} & \multicolumn{2}{|c|}{ Holo-TCII } \\
\hline & Normal & High & Normal & Low \\
\hline Pernicious anaemia & - & 9 & - & 9 \\
\hline Post-gastrectomy Cbl deficiency & - & 1 & - & 1 \\
\hline Dietary deficiency of folate $\pm \mathrm{Cbl}$ & - & 4 & - & 4 \\
\hline Chronic alcoholism & 4 & - & 1 & 3 \\
\hline Myelodysplastic syndromes & 5 & - & 3 & 2 \\
\hline Methotrexate treatment & 1 & 1 & 1 & 1 \\
\hline Azathioprine treatment & 1 & - & 1 & - \\
\hline $\mathrm{CDA}$ & 4 & - & - & 4 \\
\hline
\end{tabular}

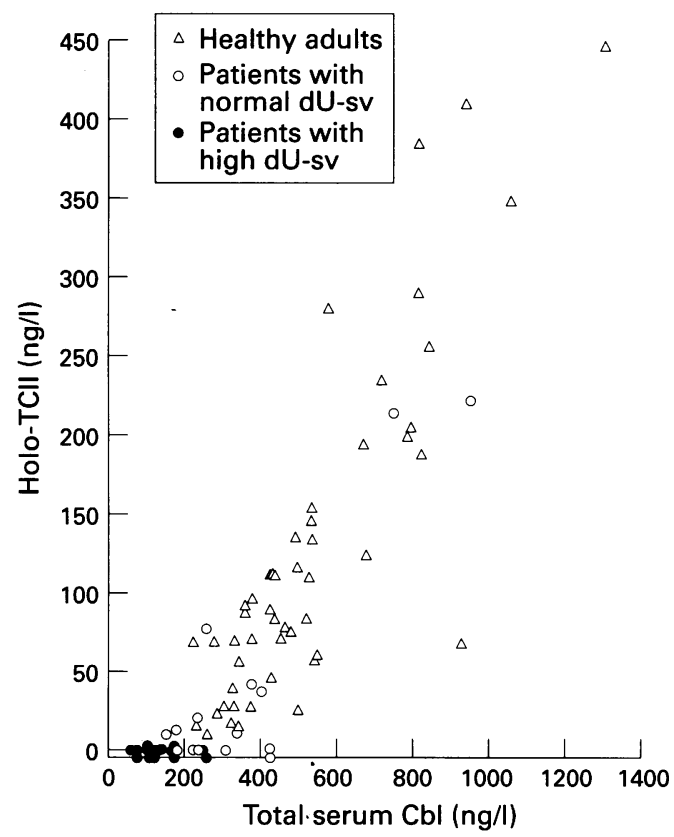

Figure 2 Relation between total serum $\mathrm{Cbl}$ and holo-TCII concentrations in 50 healthy volunteers, in 15 patients with normal deoxyuridine suppressed values ( $d U$-sv) and in 15 patients with high deoxyuridine suppressed values.

TCII concentration was found in three patients with MDS, one chronic alcoholic and one patient each on azathioprine or methotrexate.

All of the patients with pernicious anaemia or dietary folate deficiency, the patient with post-gastrectomy $\mathrm{Cbl}$ deficiency and one of the two patients on methotrexate had high deoxyuridine suppressed values-that is, they had impaired methylation of deoxyuridylate to thymidylate in their bone marrow cells. The remainder had normal values - that is, had no evidence of impairment of this $\mathrm{Cbl}$ and folate dependent reaction. The relation between the deoxyuridine suppressed values and serum holo-TCII concentrations is presented in table 1. It is evident that all 15 patients with high deoxyuridine suppressed values and nine of 15 with normal deoxyuridine suppressed values, including the four patients with CDA, had low holo-TCII concentrations. All but four of the patients with normal deoxyuridine suppressed values and low holo-TCII concentrations had normocellular marrow fragments; the four exceptions were the patients with CDA who had very hypercellular marrow fragments as a result of erythroid hyperplasia.
Figure 2 illustrates the relation between total serum $\mathrm{Cbl}$ and holo-TCII concentrations in patients and controls. It is evident that there is a considerable overlap between the results in healthy subjects and patients and between the results in patients with high and normal deoxyuridine suppressed values.

\section{Discussion}

Three methodological difficulties were identified in the measurement of serum holo-TCII concentrations by the silica adsorption method. Firstly, the lower limit for the sensitivity of most currently used methods for the measurement of $\mathrm{Cbl}$, including the $\mathrm{IM}_{\mathrm{X}} \mathrm{Cbl}$ assay, is around $60 \mathrm{ng} / \mathrm{l}$. Holo-TCII assays on serum samples giving a $\mathrm{Cbl}$ value for silica adsorbed serum below $60 \mathrm{ng} / \mathrm{l}$ will be unreliable. Secondly, treatment with silica does not result in the complete removal of holo-TCII; however, the extent of removal is high, being about $88 \%$. Thirdly, the reproducibility of holo-TCII measurements was relatively poor, partly because holo-TCII measurements are calculated as a difference between two assay results, each with its own coefficient of variation. More accurate holo-TCII measurements on serum samples with a low total Cbl concentration would require the use of the Euglena gracilis microbiological assay, which can measure $\mathrm{Cbl}$ concentrations accurately down to $20 \mathrm{ng} / 1 .{ }^{10}$

In the present study, all 10 patients with $\mathrm{Cbl}$ deficiency had undetectable concentrations of holo-TCII. However, undetectable or low concentrations were also found in patients with dietary folate deficiency, in one of the two patients on methotrexate and in a mixed group of nine patients with normal deoxyuridine suppressed values in which the diagnoses were chronic alcoholism, MDS or CDA. Thus, whereas a low holo-TCII concentration seems to be a common feature of a degree of $\mathrm{Cbl}$ deficiency which gives rise to macrocytosis and a high deoxyuridine suppressed value, it does not help in distinguishing between $\mathrm{Cbl}$ deficiency and other causes of macrocytosis.

TCII is synthesised by several cell types including hepatocytes, endothelial cells and ileal enterocytes. ${ }^{3}$ As the initial plasma half-life of human holo-TCII injected into humans and rabbits is short (about 60 minutes ${ }^{11}{ }^{12}$ ), holoTCII must be in a very dynamic state. The concentration of holo-TCII in plasma would depend on a complex balance between the rate of removal of $\mathrm{Cbl}$ from plasma holo-TCII by various cell types and the rates of entry into the plasma of new pre-formed holo-TCII molecules or generation in the plasma of holoTCII by the reaction of newly released $\mathrm{Cbl}$ with plasma apo-TCII. Newly absorbed Cbl seems to combine with apo-TCII within the enterocyte and enter the circulation as holoTCII. ${ }^{3}$ A low holo-TCII concentration may therefore result from decreased absorption of $\mathrm{Cbl}$ in the terminal ileum, a reduced rate of release of $\mathrm{Cbl}$ from the liver and other tissues for binding to apo-TCII or an increased rate of clearance of holo-TCII by binding to specific receptors on haemopoietic and other cells, or 
by some other mechanism. Previous investigators have only considered the first of these possibilities. Consequently, they have interpreted low holo-TCII concentrations in patients without haematological or biochemical changes attributable to $\mathrm{Cbl}$ deficiency as evidence of negative $\mathrm{Cbl}$ balance of recent onset due to reduce intake or absorption of this vitamin. ${ }^{45}$ Our finding of low holo-TCII concentrations in as many as $60 \%$ of patients with normal deoxyuridine suppressed values suggests that one or more of the other mechanisms mentioned above may also be important. In particular, the finding of low holo-TCII concentrations in all four patients with erythroid hyperplasia due to $\mathrm{CDA}$, indicates that noticeably increased erythropoietic activity may be an important cause of low holo-TCII concentrations. The poor precision of serum holo-TCII concentrations when measured in different assay runs by current methods must also contribute to the high prevalence of apparently low holo-TCII concentrations.

1 England JM, Down MC, Wise IJ, Linnell JC. The transport of endogenous vitamin $B_{12}$ in normal human serum. Clin Sci Mol Med 1976;51:47-52.
2 Hall CA. The carriers of native vitamin $\mathbf{B}_{12}$ in normal human serum. Clin Sci Mol Med 1977;53:453-7.

3 Rothenberg SP, Quadros EV. Transcobalamin II and the membrane receptor for the transcobalamin II-cobalamin complex. Baillieres Clin Haematol 1995;8:499-514.

4 Herzlich B, Herbert V. Depletion of serum holotranscobalamin II. An early sign of negative vitamin $B_{12}$ balance. Lab Invest 1988;58:332-7.

5 Herbert V, Fong W, Gulle V, Stopler T. Low holotranscobalamin II is the earliest serum marker for sub-normal vitamin $\mathrm{B}_{12}$ (cobalamin) absorption in patients with AIDS. Am 7 Hematol 1990;34:132-9.

6 Wickramasinghe SN, Fida S. Correlations between holotranscobalamin II, holo-haptocorrin, and total $\mathrm{B}_{12}$ in serum samples from healthy subjects and patients. $\mathcal{f}$ Clin Pathol 1993;46:537-9.

7 Matthews JH, Wickramasinghe SN. A method for performing deoxyuridine suppression tests on microtitre plates. Clin Lab Haematol 1986;8:61-5.

8 Das KC, Manusselis C, Herbert V. Determination of vitamin $B_{12}$ (cobalamin) in serum and erythrocytes by radioassay, and of holo-transcobalamin II (holo-TCII) and holo-haptocorrin (holo-TCI and III) in serum by adsorbing holo-TCII on microfine silica. $\mathcal{f}$ Nutr Biochem 1991;2:455-63.

9 Bloomfield FJ, Scott JM. Identification of a new vitamin $B_{1}$ binder (transcobalamin III) in normal human serum. $\mathrm{Br} f$ Haematol 1972;22:33-42.

10 Chanarin I (ed). Laboratory haematology. An account of laboratory techniques. Edinburgh: Churchill Livingstone, 1989:121-5.

11 Hom BL, Olesen HA. Plasma clearance of ${ }^{57}$ Cobalt-labelled vitamin $B_{12}$ bound in vitro and in vivo to transcobalamin and II. Scand $\mathcal{F}$ Clin Lab Invest 1969;23:201-11.

12 Schneider RJ, Burger RL, Mehlman CS, Allen RH. The role and fate of rabbit and human transcobalamin II in the plasma transport of vitamin $B_{12}$ in the rabbit. $\mathcal{F}$ Clin Invest 1976;57:27-38. 